DIW BERLIN

Discussion Papers

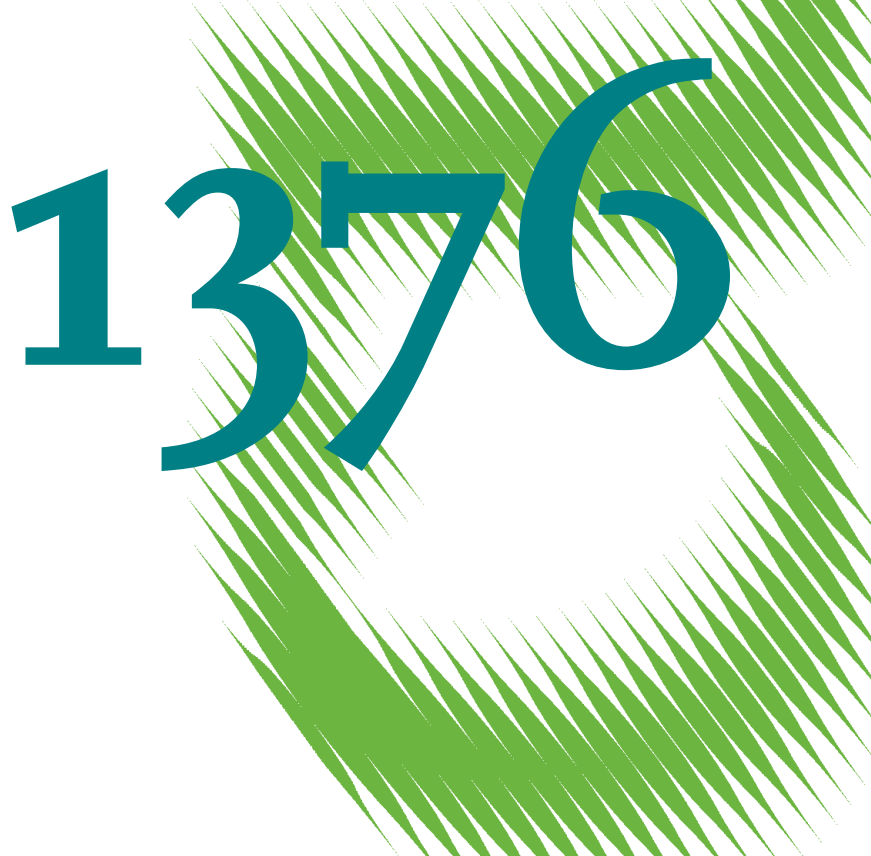

John Doe's Old-Age Provision: Dollar Cost Averaging and Time Diversification 
Opinions expressed in this paper are those of the author(s) and do not necessarily reflect views of the institute.

IMPRESSUM

(C) DIW Berlin, 2014

DIW Berlin

German Institute for Economic Research

Mohrenstr. 58

10117 Berlin

Tel. $+49(30) 89789-0$

Fax +49 (30) $89789-200$

http://www.diw.de

ISSN print edition $1433-0210$

ISSN electronic edition 1619-4535

Papers can be downloaded free of charge from the DIW Berlin website:

http://www.diw.de/discussionpapers

Discussion Papers of DIW Berlin are indexed in RePEc and SSRN:

http://ideas.repec.org/s/diw/diwwpp.html

http://www.ssrn.com/link/DIW-Berlin-German-Inst-Econ-Res.html 


\title{
John Doe's Old-age Provision: \\ Dollar Cost Averaging and Time Diversification
}

\author{
Dirk Ulbricht*
}

April 11, 2014

\begin{abstract}
Do timing and time diversification improve the average investor's stock market return? Contrary to literature's scenario of wealthy investors, average investors invest each month over life. Many purchases prevent investors from buying at peak, but horizons decrease, giving latter investments less time to offset losses. This paper accommodates timing using internal rates of return, facilitating the comparison of wealthy and average investors. One to 480 months investments in S\&P and downward trending Nikkei, are compared. In conclusion, average investor's risk and return ratios improve with horizon and, compared to wealthy investors, in bullish and deteriorate in bearish markets.
\end{abstract}

Keywords: Dollar-weighted return, retirement accounts, risk, cost averaging, DCA, time diversification

JEL Classification: G11; G17; D14

*dulbricht@diw.de, DIW Berlin, Mohrenstr. 58, 10117 


\section{Introduction}

This paper addresses the question, does John Doe's risk and return improve from investing regularly (dollar cost averaging) and over long horizons (time diversification) when investing in a diversified stock portfolio for old-age? The average investor saving for old-age earns monthly contributions to the stock portfolio over working life. Close to retirement, when most of the money is already invested, single month-on-month stock market changes may significantly alter the outcome. However, literature focuses on people already owning the whole amount to be invested from the beginning, and on yearly data. This paper follows Dichev [2007] using Internal Rates of Return (IRR) that explicitly take the timing and the amount of each contribution into account, and uses monthly data. ${ }^{1}$ In contrast to most of the empirical literature dealing with dollar cost averaging, this paper analyzes both the usual candidate, the S\&P 500, and the Nikkei, which has trended downward since its January 1990 high. It is particularly in markets that experience a protracted downward trend and that are very volatile that purchasing at many different times is potentially most helpful. Not all of the money will be invested at an initial market high reducing the average buying price.

Many industrialized countries like the USA or Germany rely on a Pay-As-You-Go pension system. This means that economically active generations pay the pensions of the retirees through their contributions in the hope that their children will keep the Generationenvertrag ${ }^{2}$ when it is their turn. This is viable as long as there are enough young to finance the system. However, as birth rates have fallen well below the level needed to prevent the population from shrinking and life-expectancies have increased, the system is bound to collapse. Consequently, a growing part of pensions need to be financed through capital investments. This is bad news for the sandwich-generation managing the change: they have to simultaneously support current retirees while saving for their own retirement. If they want to keep their living standards high, high yields and little risk are needed. With government bonds, savings accounts, and capital insurances the latter is easy to get, however quality of life will have to adjust.

There might be a way out: stocks. On average, returns of highly diversified portfolios, like the S\&P 500, are higher than riskless alternatives, such as treasury bills or bonds. However, sometimes stock investment leads to huge losses. Still, many investment advisers point out that the risks can be diversified away using timing and time.

Firstly, diversify the timing of your purchase. You can never be sure if the current price is a temporary

\footnotetext{
${ }^{1}$ IRR are also known as the dollar weighted returns (DWR). It is the single representative return that leads to the same terminal value as the actual return series.

${ }^{2}$ Intergenerational contract.
} 
market high, a market low or something in-between. With the aim of limiting the risk of buying at the wrong time, it is advisable to buy at different moments in time. Due to its intuition the strategy of dollar cost averaging (DCA) is widely accepted among investment advisers.

Secondly, diversify your investments over different market periods extending the length of the investment horizon (time diversification). From time to time markets become bearish, that is, the prices are falling, and widespread pessimism causes the negative sentiment to be self-sustaining. However, markets tend to recover, becoming bullish. Consequently, although the average return might decrease with the time horizon, risk as measured by the variance of the returns will decrease as well. More importantly, if the horizon is long enough, stock investments will always considerably outperform riskless alternatives.

In contrast to this popular view, there is no unanimity in the literature on the benefits of dollar cost averaging and time diversification. However, typically the two concepts are discussed separately. Furthermore, dollar cost averaging analysis is typically implemented by comparing the outcomes of investing a lump-sum that is available from the beginning in two different ways. In the first scenario, the whole sum is invested once in a stock portfolio for a certain horizon. In the second scenario initially the whole amount is deposited in a riskless asset. Then, each period a part is invested in stocks, while the remaining amount earns the riskless interest rate. Thereby, the risk of buying at a market high is split over multiple purchases.

However, in reality a huge number of investors regularly contribute (RC) part of their monthly income for retirement, thus simultaneously applying time diversification and DCA. Here, the whole amount of money is not available from the beginning but is created over time. Their investment is not a mixture of a riskless asset and a stock portfolio with the weights of the components changing over time. Rather, it is a sequence of lump-sum investments. The first contribution is invested over the whole investment horizon, the second contribution one period less, and so on.

The differences of regular contribution and lump-sum investments are illustrated along a simple example, showing that the returns of regular contributions more volatile as they are more sensitive to the markets close to the end of the investment horizon. A broad empirical analysis based on the returns of thousands of investors with different starting points and investment horizons compares the two types of returns for investment. This is implemented for all possible ranges for the S\&P 500 and the Nikkei up to a 480 month investment horizon from the 1950s to 2013. For the rising or sideways trending S\&P 500 it is demonstrated that time diversification and dollar cost averaging works for regular contributors: lengthening of the horizon leads to an improvement of the Sharpe ratio and reduces the probability of 
returns lower than the riskless asset. Moreover, regular contributions outperform lump-sum investments. However, the opposite results can be observed with respect to the more volatile and downward trending Nikkei. Low returns of regular contributors retiring during a prolonged downward-trend lead on average to falling Sharpe ratios and rising probabilities of lower returns than riskless assets, both with a growing investment horizon and in comparison to returns of a one-time investor. To sum up, time diversification and dollar cost averaging are beneficial if markets are bullish shortly before retirement, if markets are bearish the results are disastrous. Thus, time and timing does not necessarily improve risk and return.

Section 2 gives an overview of the relevant literature. Section 3 introduces the methodology of computing the two different measures of return and the data. Section 4 presents the results and section 5 concludes.

\section{Literature Overview}

Relying on the theory of expected utility maximization, Samuelson [1969] demonstrates that the optimal asset-allocation decision is independent of the investment horizon. However, this is based on rather strict assumptions that stock returns follow a random walk and investors exhibit constant relative risk aversion (CRRA). Allowing for mean reverting returns, Bodie [1995] shows that the cost of hedging the risks of stock market investment increases with the time horizon. Barberis [2000] demonstrates that time-variation in asset returns provides a rationale for practitioners' recommendations of investing more in risky assets when the investment horizon is long. Still, the estimation uncertainty of predictive models will largely reduce, in some cases even invert the effect.

Constantinides [1979] demonstrates theoretically that sequential investment strategies not strictly adhering to past decisions, like dollar cost averaging, but rather using upcoming information to optimize the portfolio, will lead to higher utility. Brennan et al. [2005] corroborate the superiority of flexible investment strategies. Comparing the empirical certainty equivalents of LS-DCA and lump-sum investment strategies from one to six years, they find that value-weighted portfolios outperform equal-weighted market portfolios. Value-weighted portfolios sell assets, if their relative value with respect to the other assets rises, and vice versa. Thus, this strategy is reacting to upcoming information, in the best of all cases realizing profits and buying undervalued assets.

With lump-sum investments, all of the money is immediately invested in the riskier, but also more lucrative, stock market when compared to LS-DCA. Thus, Rozeff [1994] adequately reduces the amount of money invested in the stock market after using lump-sums in order to compare the two strategies. He 
concludes that as long as there is a positive expected return, then those who hesitate, lose money. In a theoretical approach modeling stock returns as $\operatorname{ARMA}(1,1)$, Balvers and Mitchell [1997] show that a gradual market entry, even if the investments are not made at fixed amounts, represents a suboptimal strategy. Vanduffel et al. [2012] propose a static strategy consisting of purchasing a suitable portfolio of path-independent options that will dominate LS-DCA for all risk-adverse investors. They provide evidence that the relative performance of LS-DCA is worse in volatile markets, exactly when it is supposed to be most helpful.

In a closely related approach to the one presented here, Dichev [2007] introduces the concept of value-weighted returns. In contrast to the usual year-on-year returns based on the first and the last price of a security, he takes the capital in- and out-flows into account. These cash-flows are the result of for example the purchase and sale of the portfolio, stock repurchases or dividend payments. On the basis of these cash-flows he derives an internal rate of return of the portfolio. When contrasted with the return calculated as the geometric mean only taking the buying and selling price into account, he shows that the value-weighted returns are significantly lower. As he intends to contrast the classical returns to the ones found using the new methodology he compares annual returns. However, as he acknowledges, the returns are highly dependent on the path of the security over time. In contrast to our paper, his results only apply for a lump-sum investor investing at the beginning and selling at the end of the year.

Malliaris and Malliaris [2008] compare the terminal values of RC into a broad portfolio of stocks when calculated on the basis of the actual monthly return sequences to the ones calculated on the basis of the geometric mean of the monthly returns. They show that the outcomes only accidentally coincide and conclude that geometric means do not adequately reflect the term structure of returns of regular investments. They do not calculate the internal rates of returns that are necessary to compare risk and return along investment horizons, but rather present average monthly returns. They implement their analysis for intervals of twenty, thirty or forty years, starting at different points in time.

\section{Data and Method}

\subsection{Lump-sum and regular contribution}

In order to demonstrate the differences between lump-sum investments and regularly contributed investments, consider the example given in table 1. For completeness, the case of a lump-sum, which is spread over several purchasing times, is given as well, denoted by Lump-sum dollar cost averaging, (LS-DCA). 
Table 1: Interest rates: example of LS and RC

\begin{tabular}{|c|c|c|c|c|c|c|c|c|}
\hline Type & Line & & Capi & al, US & & & Retu & \\
\hline period & & 1 & 2 & 3 & Total & 1 & 2 & Total \\
\hline Lump-sum & $\begin{array}{c}\text { I } \\
\text { II }\end{array}$ & $\begin{array}{l}1 \\
1\end{array}$ & $\begin{array}{l}1.10 \\
1.10 \\
\end{array}$ & $\begin{array}{l}1.27 \\
1.27\end{array}$ & 2.53 & 10 & 15 & 12.5 \\
\hline Regular Contribution & $\begin{array}{l}\text { III } \\
\text { IV }\end{array}$ & 1 & $\begin{array}{c}1.10 \\
1 \\
\end{array}$ & $\begin{array}{l}1.27 \\
1.15\end{array}$ & 2.42 & 10 & $\begin{array}{l}15 \\
15\end{array}$ & 13.2 \\
\hline $\begin{array}{l}\text { Regular Contribution, } \\
\text { hypothetical }\end{array}$ & $\begin{array}{c}\mathrm{V} \\
\mathrm{VI}\end{array}$ & 1 & $\begin{array}{c}1.13 \\
1 \\
\end{array}$ & $\begin{array}{l}1.28 \\
1.13\end{array}$ & 2.42 & 13.2 & $\begin{array}{l}13.2 \\
13.2\end{array}$ & 13.2 \\
\hline $\begin{array}{l}\text { Lump-sum } \\
\text { dollar cost averaging }\end{array}$ & $\begin{array}{c}\text { VII } \\
\text { VIII }\end{array}$ & $\begin{array}{l}1 \\
1\end{array}$ & $\begin{array}{l}1.10 \\
1.05 \\
\end{array}$ & $\begin{array}{l}1.27 \\
1.21\end{array}$ & 2.47 & $\begin{array}{c}10 \\
5 \\
\end{array}$ & $\begin{array}{l}15 \\
15 \\
\end{array}$ & 11.2 \\
\hline
\end{tabular}

In each case two dollars are invested for a maximum of two periods and cash is withdrawn at the beginning of the third period. For illustrative purposes, each dollar is discussed separately. The results for lump-sum are reported in line I and II, for regular contribution in line III to VI, and for LS-DCA in line VII and VIII. The columns report the money at the beginning of each period for each dollar, the sum of the outcome of both invested dollars, the assumed returns each period, and the resulting overall return of lump-sum, regular contribution and LS-DCA. The assumed stock market return in period one is $y_{1}=10 \%$ and in period two is $y_{2}=15 \%$, the assumed riskless rate of return in period one (in italics) is $y_{\text {riskless }}=5 \%$.

Each dollar of lump-sum is invested over two periods, earning a return of $10 \%$ in the first and $15 \%$ in the second period, such that at the beginning of the third period, when the investment ends, the investor receives a terminal value of $T V_{L S}=\left(1+y_{1}\right) \times\left(1+y_{2}\right)$, that is 1.27 , for each of the two dollars originally invested, that is 2.53 dollars in total. The return on the investment is the hypothetical uniform return, that leads to the same terminal value given that the same amount of money is invested for the same period of time. Here, this is $y_{L S}=\left(\frac{1.27 \times 2}{1 \times 2}\right)^{0.5}-1=12.5 \%$, such that $T V_{L S}=\left(1+y_{L S}\right)^{2} \times 2=2.53$.

As Malliaris and Malliaris [2008] point out, the investment of a regular contributor can be interpreted as a combination of lump-sum investments where the investment horizon is decreasing by one period each period. The regular contributor invests one dollar in the first period for two periods so that the return of the first dollar is the same as for the two-period lump-sum investment. As the second dollar is invested only one period, its return is $15 \%$. Thus, the terminal value is $T V_{R C}=\left(1+y_{1}\right) \times\left(1+y_{2}\right)+1+y_{1}$, producing $T V_{R C}=2.42$. Again, the overall return of $\mathrm{RC}$ is the uniform return of a hypothetical 
investment that leads to the same terminal value - given identical capital invested at identical points in time, $T V_{R C}=\left(1+y_{R C}\right) \times\left(1+y_{R C}\right)+1+y_{R C}$. This return is $y_{R C}=13.2 \%$. The hypothetical investment is given in line $\mathrm{V}$ and VI.

Given that lump-sum and regular contributions both invest in the same asset and that the rate of return is standardized to reflect the percentage change of an investment over one period, returns can be compared directly to evaluate the effects of multiple buying periods on mean returns and risks of stock market investments.

One notable difference between lump-sum and regular contribution is the way different timing of stock market returns influences the overall return. For lump-sum the timing of $y_{1}$ and $y_{2}$ are irrelevant: if the two were interchanged, $y *_{1}=y_{2}$ and $y *_{2}=y_{1}, y *_{L S}=y_{L S}$ remain unaffected. Both returns thus have an equal influence on $y_{L S}$. However, while $y_{2}$ has an influence on both dollars invested for lump-sum, $y_{1}$ only has an influence on the first dollar invested for regular contribution. Changing the sequence leads to different results.

Generalizing this to a multi-period case, the first return only has an influence on the first dollar invested, the second return on the first two dollars, and the $n^{\text {th }}$ return on the first $n$ dollars. The longer the overall horizon of the entire investment, the more influence returns closer to the end have relative to returns closer to the beginning. The return prior to the sale of the portfolio is the most influential one affecting each single investments that constitute the regular contribution.

Furthermore, as regular contributions are in fact combinations of lump-sums of different investment horizons - all, except one of the integral investments have shorter horizons than a comparable lumpsum investment. So while the capital of an lump-sum investment over 40 years is completely invested over the whole investment horizon, the capital of a regular contribution of 40 years, a mere $\frac{1}{480}$ part of the originally invested capital for a monthly contributor is invested for the whole investment horizon. However, a $\frac{1}{480}$ part of the capital is invested $479,478, \ldots 2$ months, and the most recently invested one is invested only one month. Among others Malkiel [2003], p. 363, shows, that a lump-sum investment in a broad stock index of 25 years has a lower average return and a lower risk measured in terms of the standard deviation than an investment of one year. As there is no closed form solution for the calculation of returns of regular investments available, it is unclear, how the timing of the purchases affect risk and return.

Many authors have recurred to the comparison of lump-sum and Lump-sum dollar cost averaging in order to work out the effect of investing at many points in time. As for lump-sum, for an LS-DCA 
investor the whole amount of money is available right from the start. However, she chooses to invest half of the money into the stock market and the other half into a riskless asset giving a return of $5 \%$ in the first period. This is done to avoid investing all the money at the wrong moment in time, that is at a market high. In the second period, the second half including the interest earned over the first period is invested into the stock market. As all of the money is invested at the same time, the return can be calculated in the same fashion as the return of lump-sum. Given the lower return of the riskless asset, the overall return is lower than in the lump-sum case, $y_{L S-D C A}=\left(\frac{2.47}{2}\right)^{0.5}-1=11.2 \%$,

However, while LS-DCA shares the timing of the investments in the stock market with regular contribution, the whole amount that is invested is available from the start. Furthermore, introducing the riskless asset makes it a different asset class - a mixture of stocks and riskless asset. Therefore, it is more suitable to answer the question of an investor already having accumulated a certain wealth whether it is helpful to enter the stock market at once or in a delayed way. If the money is generated step by step it is not.

\subsection{Comparing results}

For a risky asset $i$ to be attractive, it has to pay a higher return than the riskless asset, that is the Excess Return, $y_{E}$ defined as the difference between the risky and the riskless return, $y_{E}=y_{i}-y_{\text {riskless }}$. Comparing two risky assets with identical Excess Returns a higher risk measured as the volatility of these excess returns is less desirable. The Sharpe ratio (SR) being the mean of the excess return over its standard deviation $(\mathrm{sd})$,

$$
S R=\frac{\text { mean }\left(y_{i}-y_{\text {riskless }}\right)}{s d\left(y_{i}-y_{\text {riskless }}\right)}
$$

takes these two aspects into account. Higher volatility of excess returns will lead to a decrease in the Sharpe ratio, whereas a higher mean excess return leads to an increasing Sharpe ratio. There is no interpretation of the Sharpe ratio below zero, that is if mean excess returns are negative. In this case, an increase of standard deviation would increase in the Sharpe ratio.

As a second indicator, the probability of negative excess returns (PNE) defined as

$$
P N E=\operatorname{Prob}\left(y_{i}-y_{\text {riskless }}<0\right)
$$

will be used. The higher it is, the less attractive investment $i$ is, as the chance that the riskless asset gives a higher return than the risky asset increases. 
Table 2: Descriptive statistics

\begin{tabular}{lcccc}
\hline & US T-Bills & S\&P 500 & Japanese T-bills & Nikkei \\
\hline Mean* & 1.01 & 16.33 & 0.69 & 26.89 \\
Stdv.* $^{*}$ & 0.15 & 2.27 & 0.29 & 3.29 \\
Median* & 1.24 & 7.76 & 0.49 & 7.50 \\
Nobs. & 683 & 683 & 703 & 703 \\
1st obs. & Feb-57 & Feb-57 & Apr-55 & Apr-55 \\
Last obs. & Dec-13 & Dec-13 & Oct-13 & Oct-13 \\
\hline *Annualized monthly real change rates & &
\end{tabular}

*Annualized monthly real change rates.

\subsection{Data and contributions}

Empirical research on dollar cost averaging and time diversification is largely based on the US markets or comparable markets in the sense that they are bearish only for some years. This might bias the results, as industrialized countries may face protracted economic difficulties. Thus, the Nikkei, downward trending since its January 1990 peak is also analyzed. Here, treasury bills (T-bills) are used as riskless assets as they have lower returns than bonds. If an investment is outperformed by treasury bills, this is a stronger indication that the respective investment is inferior to riskless assets than if bond yields were used. Furthermore, due to the short term of three month, treasury bills are easy to handle for private investors that might not want to care of term structure.

Monthly S\&P 500 (end-of-month values), three month treasury bill rates and the consumer price index (CPI) of the USA, respectively Japan are taken from Federal Reserve Economic Data. Nikkei data (end-of-month values) are taken from Datastream. The stock-market returns are deflated using CPI data. The observations range from February 1957 to December 2013 for the S\&P 500, and from April 1955 to October 2013 for the Nikkei. Table 2 presents some descriptive statistics.

The mean and standard deviation of the S\&P 500 is markedly lower than of the Nikkei. The medians are similar indicating that the means are biased by outliers. The time period covered is comparable for US and Japanese data.

It is highly unrealistic that an investor lays back an equal dollar-sum each month over longer periods such as ten years, let alone the maximum 40 years analyzed here. Following Malliaris and Malliaris [2008] the regular investor increases her contributions by a factor of five percent a year, which reflects an assumed inflation rate of two percent and growth of real gross domestic product of three percent. As the contributions grow over time, their importance for the investment grows, as well. This will reinforce the corresponding effects of investing regularly laid out in subsection 3.1 above. 


\section{Results}

Figure 1 compares the differential effect the last part of the investment period has on the overall return of a regular and a lump-sum contribution. Figures $1 \mathrm{a}$ and $1 \mathrm{~b}$ depict the monthly logarithms of the S\&P 500 and the Nikkei, starting in February 1997 and April 1997, respectively. Figures 1c and 1d show the returns of growing regular (solid lines) and lump-sum contributions (dashed lines) each investing 40 years in the S\&P 500 and Nikkei. The dates indicate the time they sell their assets. For example, the first observations in figure 1c represent the returns of an investor selling in February 1997 after investing for 40 years in the S\&P 500 .

Comparing figure 1a and figure 1c huge increases and drops from one period to the other of the logs of the indexes are clearly reflected in the regular returns plotted below. This is the case for lump-sum investments as well, however as each single return has the same influence on the overall outcome the returns do not respond as intensely to more recent history of returns. This makes regular contributors' returns more sensitive to trends than lump-sum returns: while the sideways trending S\&P 500 leads to higher regular than lump-sum returns, the Nikkei downward trending since January 1990 leads to higher lump-sum than regular returns.

The means and standard deviations of the returns of the S\&P 500 (panels a and c) and the Nikkei (panels $\mathrm{b}$ and $\mathrm{d}$ ) for all horizons from one to 480 months are given in figure 2. The returns change most markedly when extending the horizon from one to 18 months. For all types of returns and stock markets, mean returns and standard deviations fall. However, for horizons longer than ten years, the tendencies differ with respect to the type of investor and the stock exchange.

Table 3 compares the means and standard deviations (stdv.) for the S\&P 500 (column three and four) and the Nikkei (columns five and six). The results are given for the 10 year horizon investments (rows I to III) and the 40 year horizon investments (rows IV to VI) for three different types of investors: regular contributors with a contribution of five percent per year, regular contributors with a constant contribution, and lump-sum contributors.

The S\&P 500 results clearly corroborate time diversification as for all types of investment mean returns grow and standard deviations decrease with the length of the investment horizon. Mean returns nearly double for regular contributors from 2.3 to 4.5 percent for growing regular contributions while they only increase from 2.4 to 2.5 percent for lump-sum investors. The standard deviations decline sharply from 6.3 to 1.4 percentage points for growing regular contributions, and from 5.5 to 0.7 percentage points for lump-sum investors. As regular growing contributions outperform lump-sum contributions 

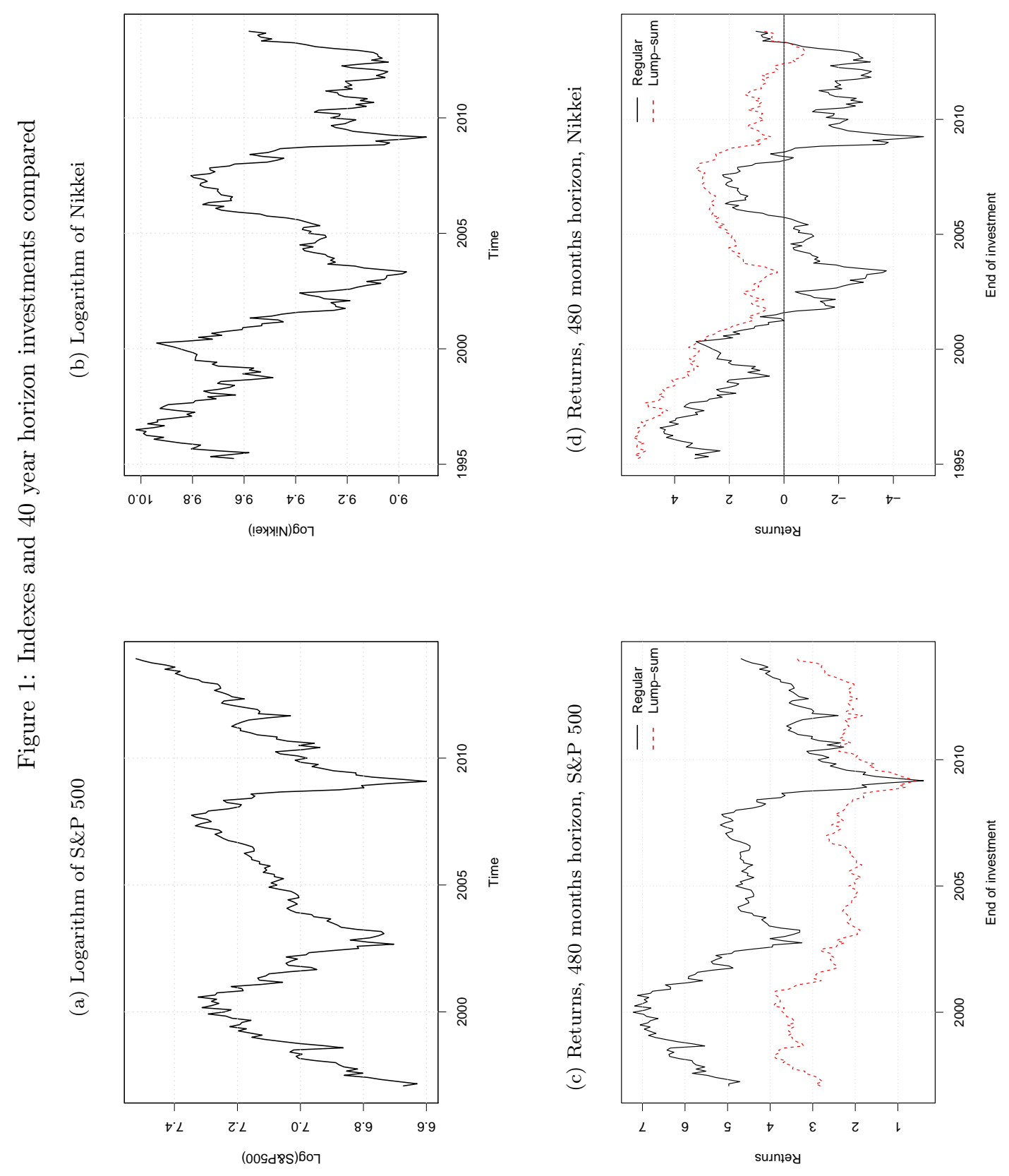

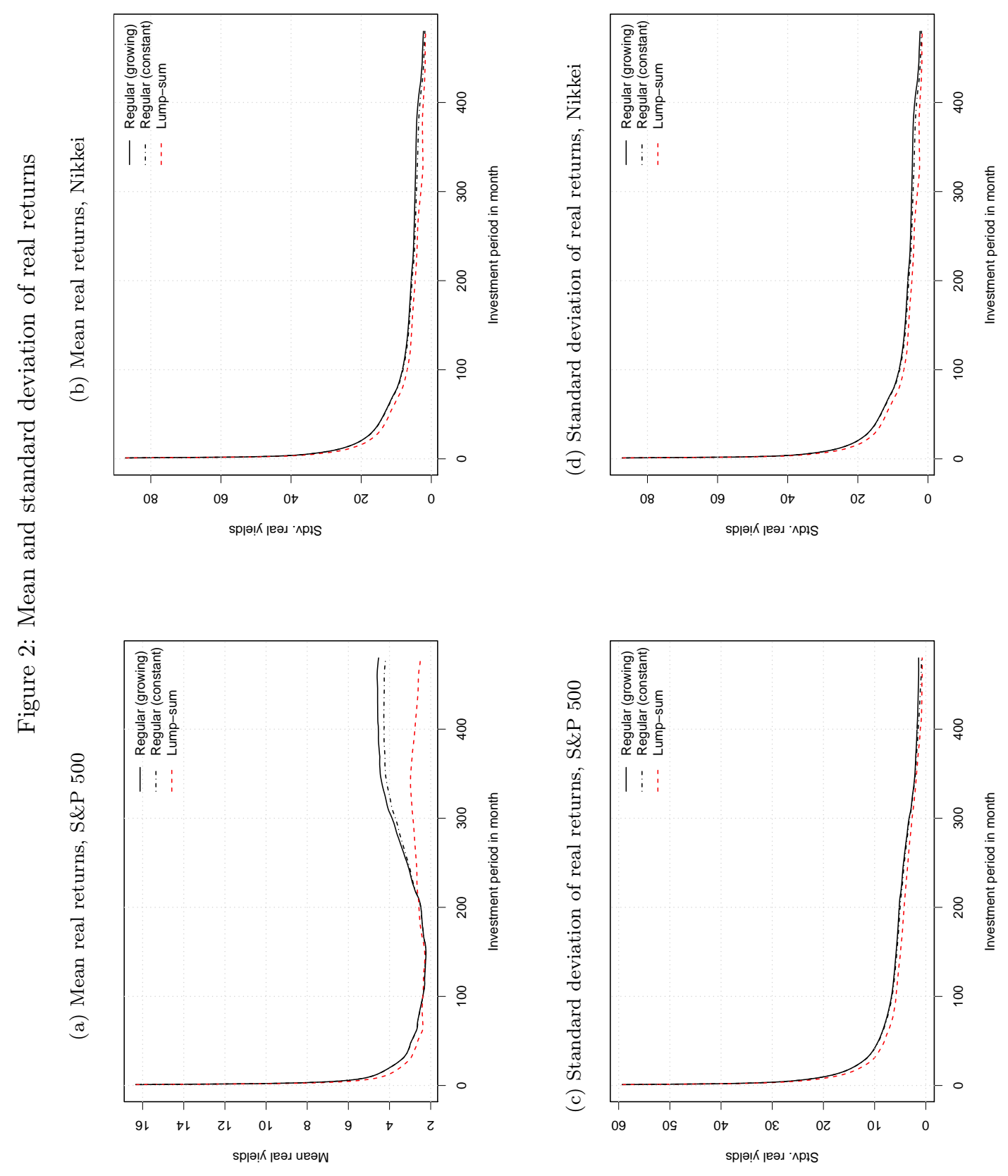
Table 3: S\&P 500 versus Nikkei: mean returns and standard deviations

\begin{tabular}{|c|c|c|c|c|c|c|}
\hline \multirow[b]{2}{*}{ Horizon } & \multirow[b]{2}{*}{ Type } & \multirow[b]{2}{*}{ Line } & \multicolumn{2}{|c|}{ S\&P 500} & \multicolumn{2}{|c|}{ Nikkei } \\
\hline & & & Mean & Stdv. & Mean & Stdv. \\
\hline \multirow{3}{*}{10 year } & Regular, growing & $\mathrm{I}$ & 2.3 & 6.3 & 2.0 & 7.3 \\
\hline & Regular, constant & II & 2.3 & 6.1 & 2.1 & 7.1 \\
\hline & lump-sum & III & 2.4 & 5.5 & 2.2 & 6.0 \\
\hline \multirow{3}{*}{40 year } & Regular, growing & IV & 4.5 & 1.4 & 0.2 & 2.3 \\
\hline & Regular, constant & $\mathrm{V}$ & 4.2 & 0.9 & 1.0 & 1.8 \\
\hline & lump-sum & VI & 2.5 & 0.7 & 2.3 & 1.6 \\
\hline
\end{tabular}

Stdv.: Standard deviation; growing contributions increase by $5 \%$ p.a.

with respect to mean returns, at the same time being outperformed with respect to standard deviations, up to now it is unclear if DCA holds.

Constant regular contributions lead to results in the middle of growing regular and lump-sum contributions. Mean returns of regular constant contributions increase a little less than growing regular contributions from 2.3 to 4.2 percent. However, standard deviation drops from 7.1 to 1.8 percentage points; 0.5 percentage points lower than the standard deviation of growing contributions for a 40 years horizon.

For the Nikkei, mean returns contradict time diversification for regular contributors, whereas it is confirmed for lump-sum contributors. For longer horizons, regular contributions are clearly outperformed both with respect to mean returns and to standard deviations by lump-sum contributions. Thus, DCA does not work here.

As the investment horizons is extended from ten to 40 years, mean returns increase slightly for lumpsum investors from 2.2 to 2.3 percent. However, mean returns drop 2.0 to 0.2 percent for growing regular contributors. The standard deviation of lump-sum investments drops from 6.0 to 1.6 percentage points while it drops from 7.3 to 2.3 percentage points for growing regular investments.

Again, constant regular contributions give results in between growing regular and lump-sum investments. Mean returns drop from 2.1 to 1.0 percent, and the standard deviation from 7.1 to 1.8 percentage points.

Figure 3a shows the probability of negative excess returns for the S\&P 500 for all horizons from one to 480 months. For all types of investors the probability is about 40 percent up to 200 month horizon. Then, it drops more or less linearly to about zero for 390 month horizons for regular contributors with growing contributions and 400 month horizons for constant regular contributors. For lump-sum investors, 
the probability starts to fall for horizons longer than 300 months. However, it drops more abruptly such that the probability is about zero for 400 month horizons as well.

Figure $3 \mathrm{~b}$ gives the corresponding results for the Nikkei. While the probability falls from 40 percent to 35 percent from one to 200 month horizons for both regular contributors, it increases for horizons from 200 to 480, reaching levels of 55 percent for growing contributions and 45 percent for constant contributions. For lump-sum investors the probability is falling starting from 100 month horizons to about five percent for 480 month horizon investments.

The Sharpe ratios for S\&P 500 investments given in figure 3c grow exponentially for all types of investors starting from about 0.25 for one month horizon investments. For regular constant contributors the Sharpe ratio grows to 3.5 , for regular contributors with a growing contribution to 2.75 , and for lump-sum investors to about 2.0. The level of Sharpe ratios of Nikkei investments in figure $3 \mathrm{~d}$ start at about 0.25 for one month horizon investments, as well. It is rising with the length of investment horizon for lump-sum investors, though less rapidly than for S\&P 500 investments, to about 1.5 for 480 month horizon. It is flat for constant regular contributors and falling for growing regular contributions. For the latter, it becomes negative for horizons greater than 438 months, dropping to 0.2 for 480 month horizon. ${ }^{3}$

\section{Conclusion}

Summing up, time diversification and dollar cost averaging extend the possible outcomes both positive and negative for John Doe investors. Slavishly sticking to an investment plan does not turn stock market investments into riskless investments.

Dollar cost averaging and time diversification are two major arguments put forth by investment advisers promoting diversified stock portfolios as not only as highly profitable but also as close to riskless investment: investing part of the monthly income is beneficial insofar as the risk of buying at the wrong moment is automatically reduced. Thus, if the investor is patient enough, the risk of incurring a loss when compared to riskless assets is reduced to zero. Though time diversification and dollar cost averaging have been discussed lengthily for lump-sum investors, the effects of the two concepts combined on regular investors saving for old-age is mostly been neglected by literature. However, this large group of investors does not decide about what to do with an existing wealth. Here, each investment is generated over time and has a different investment term. Furthermore, investments close to retirement are very short-term and have a huge impact on the outcome. This paper tries to fill the gap applying dollar-weighted returns

\footnotetext{
${ }^{3}$ Negative Sharpe ratios can not be interpreted, see subsection 3.2 on page 8
} 

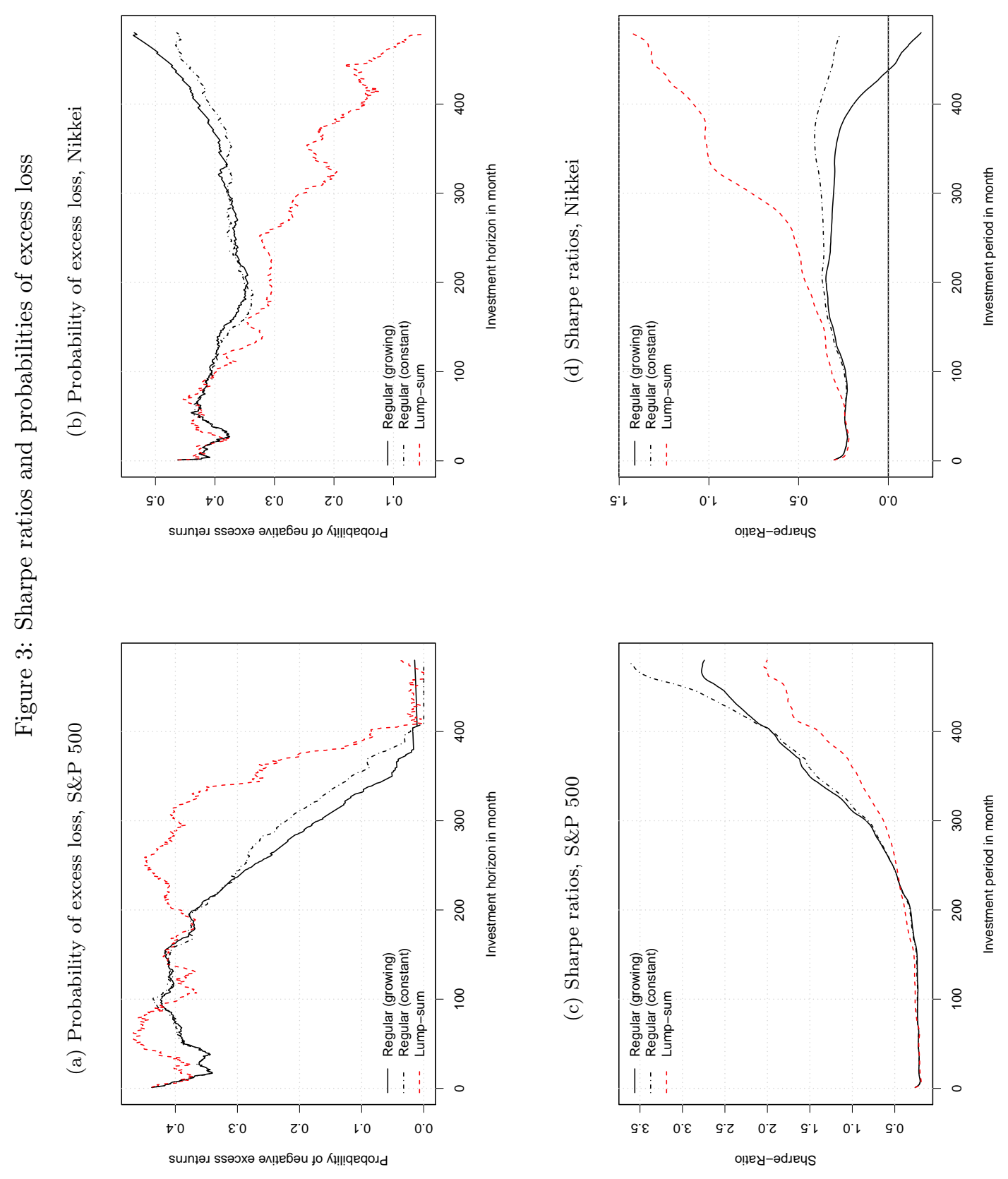
on monthly data in order to explicitly account for the term structure and the importance of the returns of last month before retirement.

A simple example reveals that returns of the underlying assets are more important for regular investments the closer they are to the end of the investment. This makes regular contributions more dependent on trends close to retirement. As there is no closed form solution for the returns of regular contributions, an empirical analysis is implemented. In order to fully assess risk, the downward trending Nikkei is contrasted with the S\&P 500, which is at the center of most of the literature. Investors with and without initial wealth are compared for investments ranging from one to 480 months.

Time diversification is confirmed for regular and lump-sum investors for the S\&P 500, which has either been trending upwards or sideways over the sample period. Mean returns and Sharpe ratios rise while the probability of negative returns compared to the riskless asset as well as the volatility fall for both. Against the background of the positive US market, regular contributors benefit from dollar cost averaging mean returns for 40 years investment being $40 \%$ higher, the Sharpe ratio being $80 \%$ higher, and the probability of negative returns beginning to fall 110 months earlier than for lump-sum investors.

However, for the Nikkei, which has trended downward since the beginning of the 1990s, time diversification only works for lump-sum investors. For regular investors, mean returns drop to 0.2 percent, the Sharpe ratio falls, even becoming negative for horizons larger than 438 months, and the probability of negative excess returns increases with the investment horizon. Consequently, as lump-sum returns largely outperform regular returns, dollar cost averaging is detrimental. Furthermore, a comparison of constant and growing regular contributions reveals, that growing contributions tend to reinforce these results.

International diversification might be a way of hedging against prolonged downward trends. However, if this works for regular investors is an empirical question left for future research. 


\section{References}

Ronald J. Balvers and Douglas W. Mitchell. Autocorrelated returns and optimal intertemporal portfolio choice. Management Science, 43(11):1537-1551, 1997.

Nicholas Barberis. Investing for the long run when returns are predictable. The Journal of Finance, 55 (1):225-264, 2000.

Zvi Bodie. On the risk of stocks in the long run. Financial Analysts Journal, pages 18-22, 1995.

M.J. Brennan, F. Li, and W.N. Torous. Dollar cost averaging. Review of Finance, 9(4):509-535, 2005.

G.M. Constantinides. A note on the suboptimality of dollar-cost averaging as an investment policy. Journal of Financial and Quantitative Analysis, 14(2):443-450, 1979.

Ilia D. Dichev. What are stock investors' actual historical returns? evidence from dollar-weighted returns. The American Economic Review, pages 386-401, 2007.

Burton G. Malkiel. A random walk down Wall Street: the time-tested strategy for successful investing. WW Norton \& Company, 2003.

A.G. Malliaris and Mary E. Malliaris. Investment principles for individual retirement accounts. Journal of Banking \& Finance, 32(3):393-404, 2008.

M. Rozeff. Lump-sum investing versus dollar-averaging. Journal of Portfolio management, pages 45-50, 1994.

P.A. Samuelson. Lifetime portfolio selection by dynamic stochastic programming. The Review of Economics and Statistics, 51(3):239-246, 1969.

Steven Vanduffel, Ales Ahcan, Luc Henrard, and Mateusz Maj. An explicit option-based strategy that outperforms dollar cost averaging. International Journal of Theoretical and Applied Finance, 15(02), 2012. 